\title{
Potential extreme events in the Polish wind energy sector, based on historical data
}

\author{
Jakub Jurasz ${ }^{1, *}$, Jerzy Mikulik ${ }^{1}$, Bartłomiej Ciapała ${ }^{1}$ \\ ${ }^{1}$ AGH University, 30 Mickiewicza Ave., 30-059, Kraków, Poland
}

\begin{abstract}
Wind energy is beginning to play a significant role in the Polish energy sector, in terms of both installed capacity and delivered energy. However, as a highly variable source, wind energy makes management of the power system complicated, especially when extreme events occur. Therefore, the objective of this paper was twofold. Firstly, it aims to simulate the operation of the Polish wind sector based on available satellite-derived wind speed data and the known spatial distribution of wind parks. Secondly, based on the created model and hourly wind speed values covering the period 01.1980-08.2017 we have analysed the statistical parameters of potential wind generation, concentrating mainly on extreme events (such as low generation and ramp rates). The results show that for an installed capacity of $5.8 \mathrm{GW}$ the likelihood of generation going below $250 \mathrm{MWh}$ for 1 hour is $0.26 \%$, and, for 5 hours, is $0.1 \%$. Ramp rates exhibit significant seasonal patterns and the highest (on an hourly time scale) can be as much as 1,295 MWh and -1,698 MWh (up and down, respectively).
\end{abstract}

\section{Introduction}

Since almost its very beginning the Polish energy sector has been dominated by conventional power plants burning hard coal and lignite, which are abundant in this region. However, economic, political and environmental reality is slowly changing the structure of the energy mix. More and more renewable energy sources (RES) are being added to the generating potential. Investments in wind energy led to installed capacity reaching almost $6 \mathrm{GW}$ by the end of the year 2017, which was about $14 \%$ of the power system potential and contributed to covering $7.5 \%$ of demand [1]. The dynamics of wind sector development in Poland are presented in Fig. 1.

Considering the fact that wind generation is intrinsically variable in nature as a result of sudden weather changes (mainly in wind speed), and that it is a non-dispatchable source, integrating it into the power system is complicated [2]. Although many methods have been proposed for predicting wind turbine energy yield (both short- and long-term) [3] there is still a need to explore and analyse the likelihood of extreme events occurring. In this paper we will concentrate only on situations in which energy generation from wind parks is at its lowest or exhibits significant ramp rates. We will analyse the probability of events lasting from one to several hours. By 'an event' we mean a situation in which the energy generated by the wind

\footnotetext{
*Corresponding author: jakubkamiljurasz@gmail.com
} 
sector is less than a given percentage of its potential. For example, the probability of three consecutive hours during each of which the generated energy was below $500 \mathrm{MWh}$.

In terms of the literature, over recent years several studies have been dedicated to the idea of using satellite-derived data to simulate the behaviour of the wind power sector. The works mentioned below constitute the theoretical basis of our study.

[4] simulated the Swedish wind sector based on MERRA (Modern-Era Retrospective analysis for Research and Applications) satellite data sets and suggested using daily and seasonal correction factors to improve the model performance. A broader study [5] dealt with the wind sector on the European scale, and compared the impact of variations in dataset resolution on simulation quality. [6] has shown that reanalysis data may sometimes be more effective than mast-based simulations, and that they offer numerous advantages. [7] made effective use of reanalysis data to simulate both the potential behaviour of multiple wind parks on the Great Plains (USA) and how their spatial distribution may reduce the coefficient of variation.

The following subsection briefly introduces the data and methodology used; the second discusses the results, and the last sums up the main conclusions and future research directions.

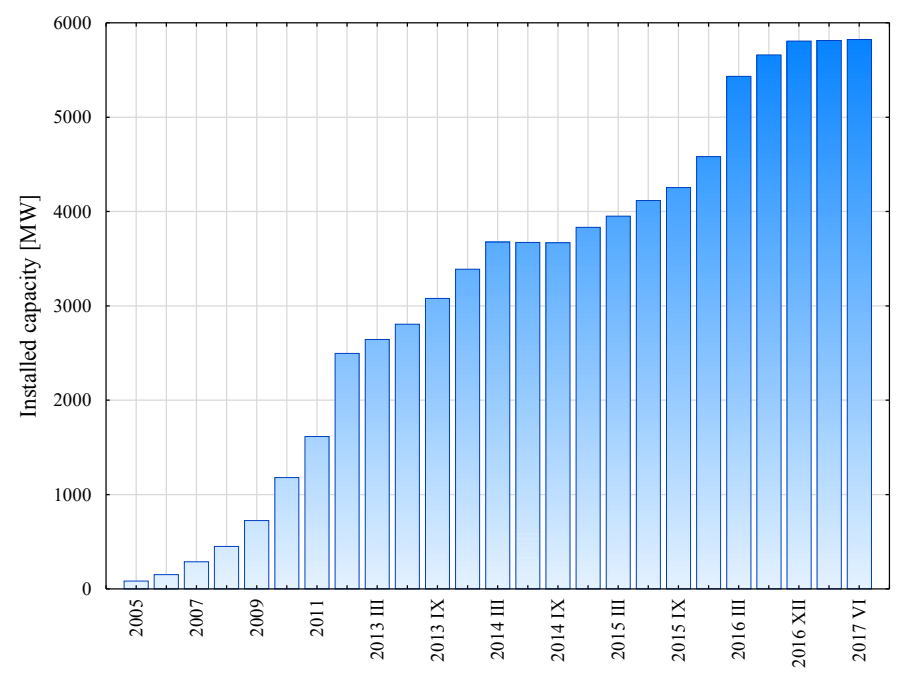

Fig. 1. Development of installed capacity in Polish wind sector [8].

\section{Input data, methods}

For the purpose of this study we have used data on hourly wind sector generation in Poland available at [9] and covering the period 09.2016-08.2017. As seen in Fig. 1 this period is also one in which the wind power potential in Poland was fairly stable, and therefore easier to simulate. The spatial distribution of wind parks (in terms of numbers per district) was downloaded from [8]. Historical (1980-2017) hourly wind speeds were obtained from [10], where they are available at $50 \times 50$-kilometre resolution. Former studies $[11,12]$ have shown that they correlate relatively well with ground measurements in terms of daily and monthly averages. Historical time series were downloaded for the locations shown in Fig. 2, which encompasses the whole of Poland. We obtained data covering the whole of Poland, but it must be clearly stated that the majority of wind parks is located in northern Poland. 


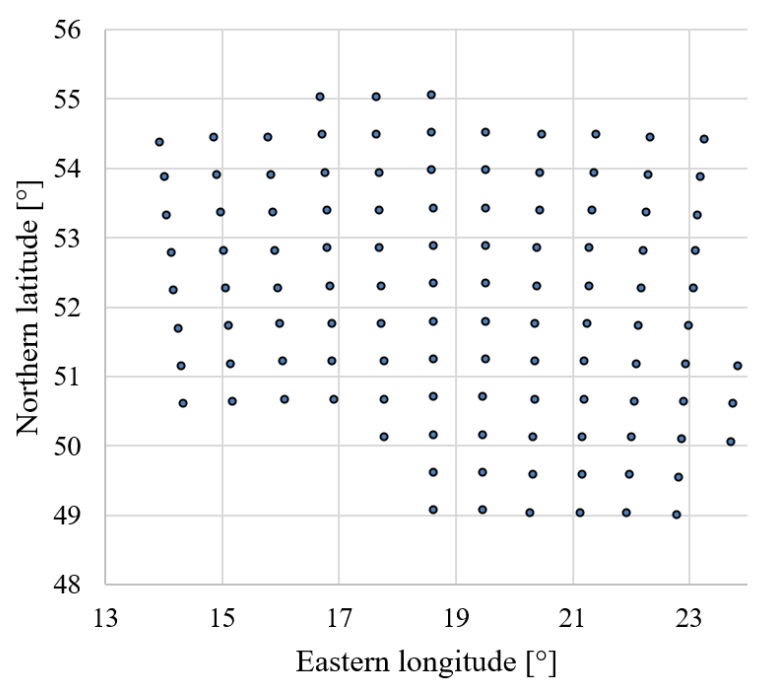

Fig. 2. Distribution of points for which wind time series was gathered.

\subsection{Simulating the wind power sector: procedure}

Knowing the wind speeds (at each location $i$ ), we recalculated them to $100 \mathrm{~m}$ a.g.l. (wind turbine hub height) using the power law and an $\alpha$ exponent of 1/7. To simulate the power/energy generation at each location we used Vestas V90 2MW [13] power curve (which is commonly used in the wind energy sector). To some extent, the distribution of wind parks in Poland was known, and we therefore applied the following formula in order to calculate the aggregated energy generation on the national level:

$$
E=\sum_{i=1}^{n} E_{i} N_{i} \beta_{i}
$$

where: $E$-aggregated energy generation on the national level [MWh], $E_{i}$ - energy generation at location $i$ from a single $2 \mathrm{MW}$ wind turbine [MWh], $N_{i}$ - number of $2 \mathrm{MW}$ wind turbines at location $i$ [integer], $\beta_{i}$ - variable used to compensate for poor spatial resolution of wind data and limited knowledge of wind park locations [-].

\subsection{Time series similarity}

For optimisation purposes a similarity criterion based on Euclidian distance [14] was used. In other words, the objective function of the optimisation problem was to make the time series as similar to one another as possible. However, to assess the quality of our simulation model we compared the observed and modelled time series in terms of the following criteria: basic statistical parameters including, mean, standard deviation, coefficient of variability and variance; coefficient of correlation; and $\mathrm{R}^{2}$. Additionally, a histogram of both time series was created to see their similarity in terms of the distribution of certain ranges. The statistical parameters presented above are included in this study to be used as a benchmark for our further research. 


\section{Results and discussion}

\subsection{Wind sector modelling}

The poor spatial resolution of satellite-derived data and its inability to adequately represent local wind patterns made precisely simulating the Polish wind energy sector more complicated. After solving the optimisation problem (by using the default settings of the inbuilt MS Excel non-linear Solver) for the considered period (09.2016-08.2017) we calculated the basic statistical parameters for both time series (simulated and observed), as shown in Table 1. As can be seen, they are similar not only in terms of averages but, most importantly, in terms of the coefficient of variation (which combines the mean and the standard deviation).

Table 1. Statistical parameters of simulated and observed hourly energy generation, AVG - average, STD - standard deviation, CV - coefficient of variability, and VAR - variance.

\begin{tabular}{|c|c|c|}
\hline & Simulated & Observed \\
\hline AVG [MWh] & $1,456.27$ & $1,495.82$ \\
\hline STD [MWh] & $1,199.14$ & $1,207.90$ \\
\hline CV [\%] & $82.34 \%$ & $80.75 \%$ \\
\hline Sum [TWh] & 12.76 & 13.10 \\
\hline VAR [-] & $1,437,933$ & $1,459,026$ \\
\hline
\end{tabular}

In modelling highly variable time series it is important to register the occurrence of extreme phenomena. In our case, these were low energy generation values. Therefore, on a histogram (Fig. 3) we have compared the distribution of both time series for values lower than $35 \%$ of the installed capacity potential. This chart clearly shows that we were able to almost perfectly model the observed time series, with the exception of values ranging from $750 \mathrm{MWh}$ to $1 \mathrm{GWh}$, where the simulation significantly overestimates the number of instances.

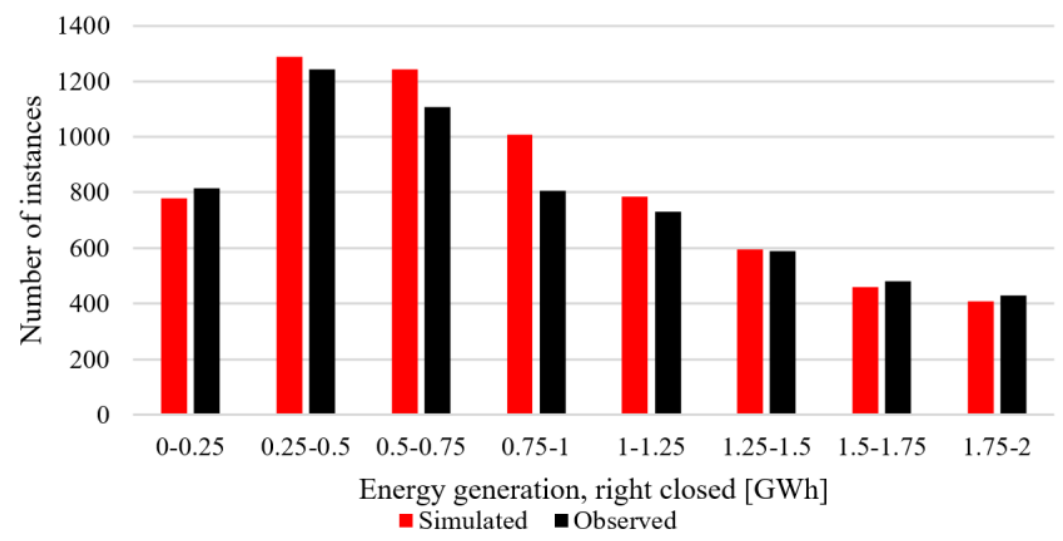

Fig. 3. Histogram of hourly simulated and observed energy generation, (left part of range only).

The remaining statistical parameters showed the model's good ability to simulate wind sector behaviour. The Pearson coefficient of correlation and the coefficient of determination $\left(\mathrm{R}^{2}\right)$ hourly, daily and monthly sums of energy generation were: $0.899,0.982,0.983$ and 
$0.808,0.963,0.965$, respectively. Fig. 4 shows the model's performance over three exemplar consecutive days. Over several hours there is an almost perfect fit, but significant discrepancies can also be seen.

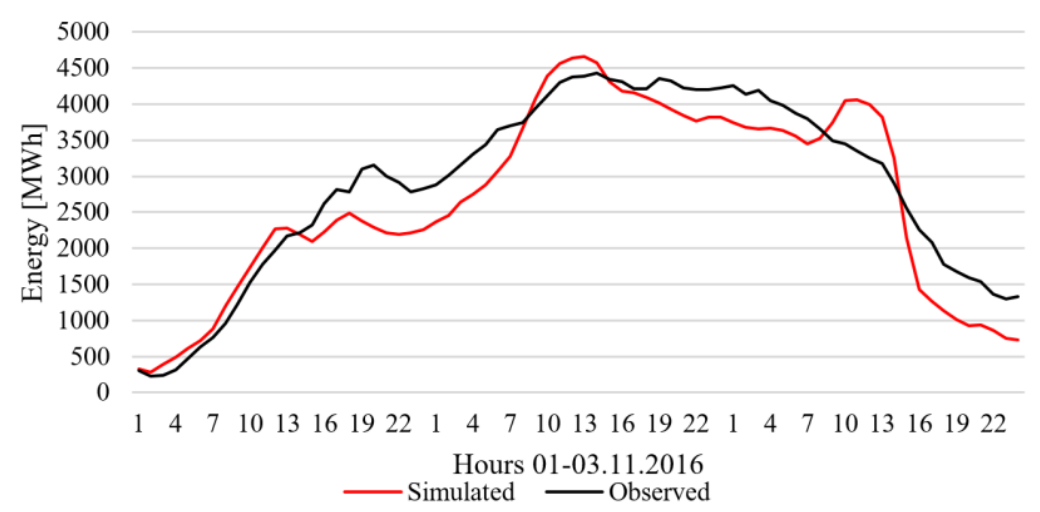

Fig. 4. Simulated and observed energy generation from wind turbines.

\subsection{Low-generation events}

The objective of our study was to analyse the likelihood of extreme events. In order to do so we simulated the theoretical behaviour of the Polish wind energy sector based on a 37-yearlong hourly wind time series. In this research we have limited our analysis to events lasting up to five hours and ranging in terms of observed energy generation from 0 to $1.5 \mathrm{GWh}$. It must be emphasised that the energy generation under consideration always relates to an installed capacity of $5.8 \mathrm{GW}$.

Our calculations showed that, over the study period, energy generation will be less than $250 \mathrm{MWh}$ for a single hour 859 times, and the probability of such event is as low as $0.26 \%$. Of course the likelihood of events lasting more than one hour is much smaller; for example, the probability of two consecutive hours of hourly generation below $250 \mathrm{MWh}$ is $0.21 \%$, and for five hours of such low generation is only $0.1 \%$.

Obviously, as shown in Fig. 5, the likelihood of each event differs over the year. A further statistical analysis showed that the probability of each event is rather strongly correlated with the mean energy generation of the month in question $\left(\mathrm{R}^{2}>0.8\right)$. In other words, months which usually have higher wind speeds are less likely to experience extremely low energy generation. Interestingly, the event probability distribution is highly uneven across the year. For example, a one-hour event of generation below $250 \mathrm{MWh}$ is six times more likely in May than in January but, at the same time, a five-hour event of generation below $250 \mathrm{MWh}$ is only 2.5 times more likely in May than in January.

The results of our analysis show that the probability of an extremely low energy supply from the wind energy sector is relatively small but shows significant seasonal variability. This variability is not only visible on the hourly scale but also on the annual scale. The simulation shows that for an installed capacity of $5.8 \mathrm{GW}$ the mean annual energy yield should be $12.76 \mathrm{TWh}$. However, the inter-annual variability of wind speeds may lead to energy generation as high as $14.58 \mathrm{TWh}$ or as low as $10.81 \mathrm{TWh}$. This clearly shows that integrating significant capacity of wind sources to the power system should consider not only hourly, but also inter-annual, variability. 

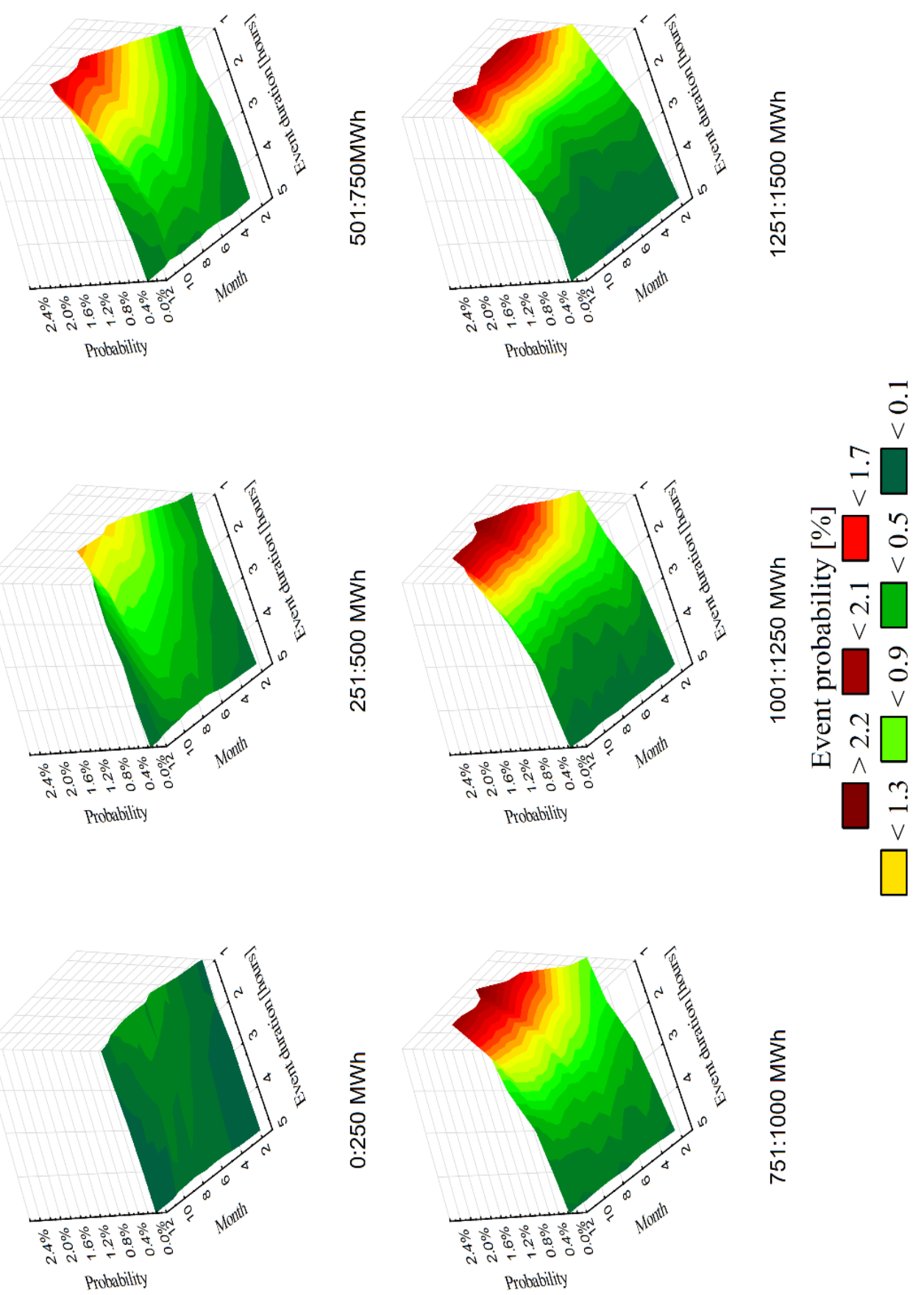

Fig. 5. Probability of 1- to 5-hour events with hourly energy generation in the ranges shown under each chart. 


\subsection{Ramp rates analysis}

The last part of our study was the analysis of ramp rates. This term refers to the rate at which a property (in this case energy generation from the wind sector) increases or decreases over time. Ramp rates are an intrinsic part of VRES generation. At the same time, VRESs constitute a significant share of the power system's installed capacity, so, if ramp rates are not predicted accurately, undesired events may be observed, such as blackouts, power curtailments or energy price increases or decreases.

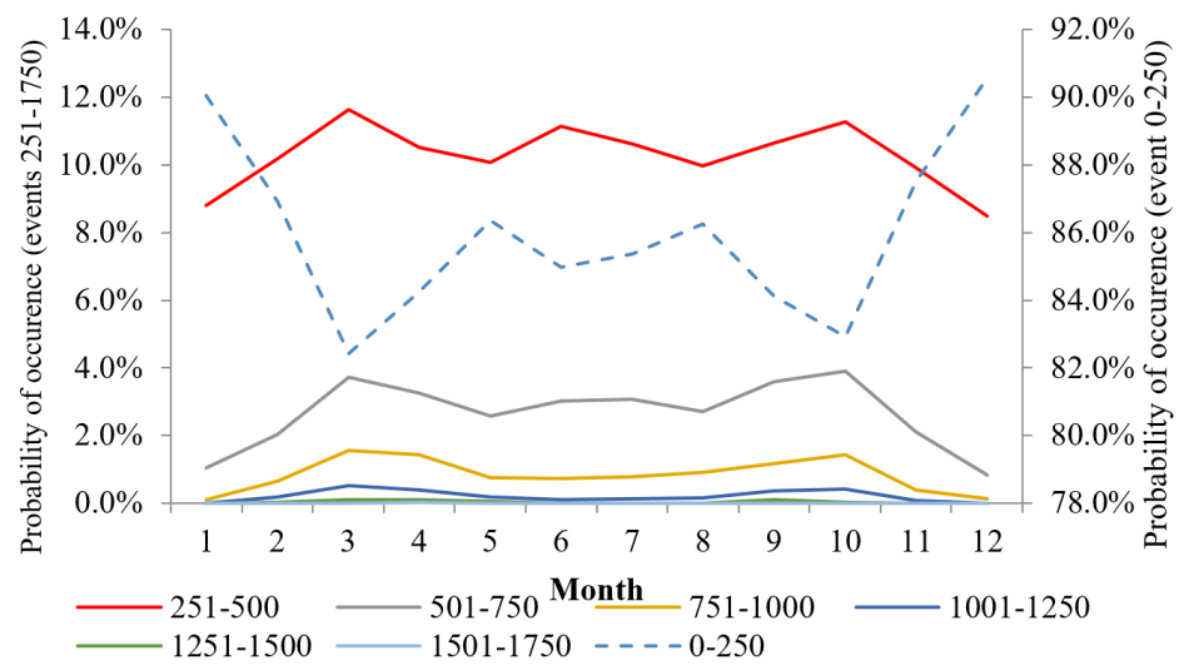

Fig. 6. Probability of ramp-downs of various ranges (for example 0-250 MWh) observed on an hourto-hour basis.

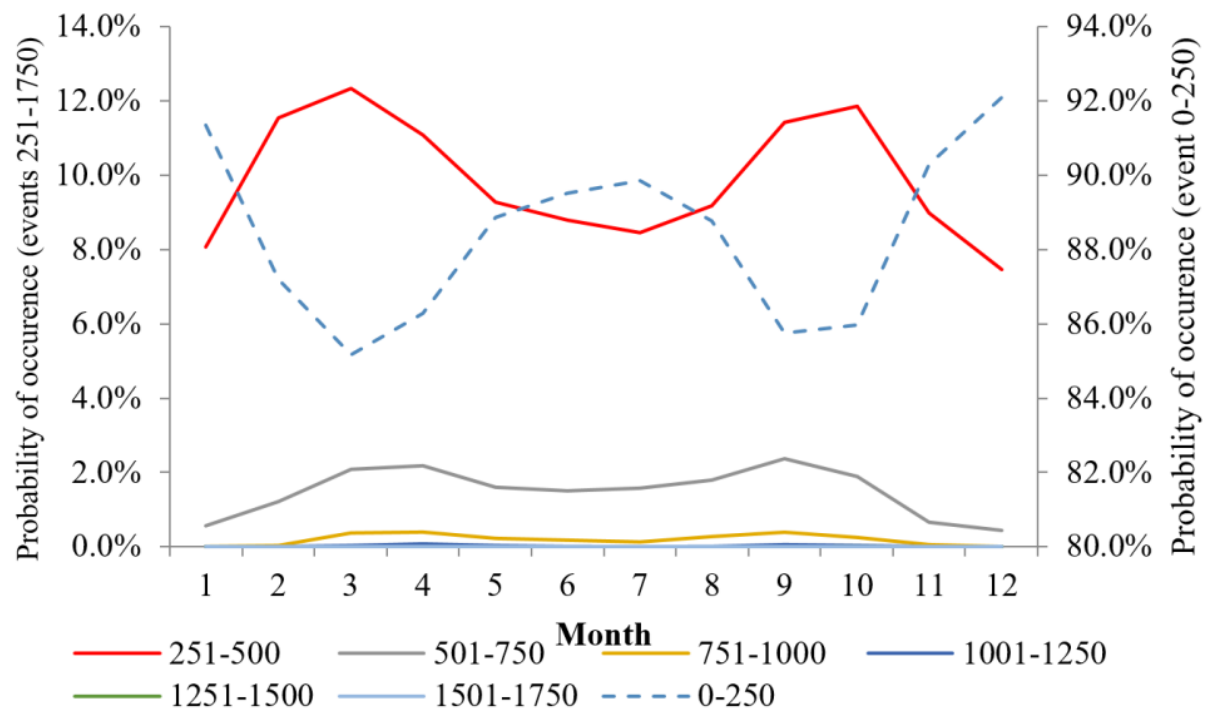

Fig. 7. Probability of ramp-ups of various ranges (for example $0-250 \mathrm{MWh}$ ) observed on an hour-tohour basis. 
Our analysis shows that ramp rates also exhibit significant seasonal variability (see Figs. 6 and 7). Although they are dominated by values ranging from 0 to $250 \mathrm{MWh}$ (about $4 \%$ of the theoretical potential), ramps down and up of more than 1,500 may also occur. For both ramp-ups and ramp-downs we see that the highest probability is in terms of ramps ranging from 251 to $500 \mathrm{MWh}$ (apart from ramps ranging from 0 to $250 \mathrm{MWh}$, obviously). Interestingly, the ramp-downs exhibit smaller seasonal variability than ramp-ups. Situations in which the ramp rate is greater than $500 \mathrm{MWh}$ are relatively unlikely (depending on the month, the likelihood is usually less than $4 \%$ ). However, looking at it as a whole, it seems that sudden ramp-downs are definitely more likely than sudden ramp-ups.

A follow-up study is undoubtedly needed to analyse the potential impact that increasing installed capacity in wind generation - and the accompanying ramp rates and extreme events - would have on the functioning of the power system, and which measures could be applied to facilitate VRES integration.

\section{Conclusions}

This research has shown that modelling the Polish wind energy sector based on satellitederived data and information on installed capacity at the district level is an arduous task. Obviously, follow-up studies are needed in order to improve simulation quality and the credibility of the results. The conducted analysis revealed that for 5,800 MW of installed capacity, extreme events (such as generation below $250 \mathrm{MWh}$ for five consecutive hours) are relatively unlikely, but the whole wind sector tends to exhibit significant ramp rates of as much as even 1,600 MW per hour. At this point we want to highlight that we are aware of the fact that the results presented here are only as valid as the quality of the simulation model's performance.

In the future we would like to use wind speed data obtained from ground measurements and see how they affect the modelling results. Additionally, we would like to see how adding solar potential (photovoltaics) may or may not reduce the variability of VRES generation.

\section{References}

1. http://stat.gov.pl/ accessed on: 10.01.2018

2. A. Kies, B. U. Schyska, L. von Bremen, Energies 9(11), 955 (2016)

3. M. Lei, L. Shiyan, J. Chuanwen, L. Hongling, Z. Yan, Renew. Sust. Energ. Rev. 13(4), 915-920 (2009)

4. J. Olauson, M. Bergkvist, Renew Energ, 76, 717-725 (2015)

5. I. González-Aparicio, F. Monforti, P. Volker, A. Zucker, F. Careri, T. Huld, J. Badger, Appl. Energ. 199, 155-168 (2017)

6. M. L. Kubik, D. J. Brayshaw, P. J. Coker, J. F. Barlow, Rene. Energ. 57, 558-561 (2013)

7. S. Rose, J. Apt, Rene. Energ. 83, 963-969 (2015)

8. https://www.ure.gov.pl/uremapoze/mapa.html accessed on: 10.01.2018

9. https://www.pse.pl/dane-systemowe/funkcjonowanie-kse/raporty-dobowe-z-pracykse/generacja-zrodel-wiatrowych accessed on: 10.01.2018

10. http://www.soda-pro.com/web-services/meteo-data/merra accessed on: 10.01.2018

11. J. Jurasz, A. Piasecki, M. Wdowikowski, E3S Web Conf. 10, (2016)

12. J. Jurasz, M. Wdowikowski, B. Kaźmierczak, P. Dąbek, E3S Web Conf. 22, (2017)

13. https://www.vestas.com/en/products/turbines/v90-2 0 mw accessed on: 10.01.2018

14. J. Serra, J. L. Arcos, Knowl.-Based Syst. 67, 305-314 (2014) 